\title{
Capillary water effect on building stones and its variation with climate change
}

\author{
Adele Salvi ${ }^{\mathrm{a}, \mathrm{b}}$, Beatriz Menéndez ${ }^{\mathrm{b}}$ \\ a University of Bologna, Bologna, Italy \\ b Geosciences and Environment Cergy, CY Cergy Paris University, Cergy-Pontoise, France
}

\begin{abstract}
Water is the most important external factor controlling weathering of building materials. We study the effect of capillary water under different environmental conditions. We experimentally simulate in the laboratory natural weathering as a function of capillarity, salt content in the water and freeze/thaw cycles with pure water and salt solutions. Then, we establish the critical parameters controlling weathering degree and velocity for selected stones. Finally, we use climate data from meteorological records and from climate models to compare past behavior of stone with future one. In selected places, where water table is close to the surface, we establish its level variation during long periods with meteorological parameters to model the evolution of water table in future climate.
\end{abstract}

Peer-review under the responsibility of the organizing committee of the ICMB21.

Keywords: capillary water; stone weathering; climate change

\section{Introduction/Background}

Water is the most important agent in building stone degradation. Water can get into walls by two different ways, either from the stone surface or from the ground. Sources of water coming from the surface are mainly rain or surface running water but also water from air moisture. In all these cases water content into the wall depends on wall orientation and architectural/mainten ance aspect (gargoyle position, condition of gutter). Ground water depends on soil draining conditions but also on water table level. In general, we can say that water content in building depends on anthropic factors (building construction choices and maintenance, soundings urban arrangement) but also on meteorological ones like raining, temperature and relative humidity.

This abstract presents ongoing research consisting in laboratory studies and weathering models based on climate conditions in France. We used a well-known methodology based on comparing past effect of some weathering agent, using weather data from Météo France, and possible future behavior estimated using data from Météo France regional climate models. Several aspects are considered in this work: a) determination of liquid and vapor water sorption/absorption kinetics; b) study of the effect of water salt content on wetting/drying and thaw/freeze weathering processes; c) estimation of weathering degree variations with climate change.

\section{Materials and methods}

\subsection{Materials}

In order to tests hydric and weathering behavior in laboratory five limestones have been selected: Maastricht, Migné, Loire Tuffeau, Lutetian "Roche Franche" and Savonnières. We chose these stones because they are largely used as building materials and very well characterized by many studies. Calcareous rocks are more sensitive to water effect than siliceous ones and so they can be easily weathered in laboratory. The properties of the studied stones are quite different which allows us to cover a large range of physical properties. Table 1 shows some physical properties of the selected stones as well as average mineralogical composition.

Table 1. Average studied stones properties.

\begin{tabular}{|c|c|c|c|c|c|}
\hline Stone & $\begin{array}{l}\text { Mineralogical } \\
\text { composition }\end{array}$ & Open porosity & $\begin{array}{l}\text { Main pore } \\
\text { diameter }\end{array}$ & $\begin{array}{l}\text { Capillarity } \\
\text { coefficient }\end{array}$ & $\begin{array}{c}\text { Uniaxial } \\
\text { compressive } \\
\text { strength }\end{array}$ \\
\hline Maastricht & Calcite, quartz & $53 \%$ & $30 \mu \mathrm{m}$ & $3 \mathrm{~kg} \mathrm{~m}^{-2} \mathrm{~s}^{-0.5}$ & $2 \mathrm{MPa}$ \\
\hline Migné & Calcite & $32 \%$ & $1 \mu \mathrm{m}$ & $0.3 \mathrm{~kg} \mathrm{~m}^{-2} \mathrm{~s}^{-0.5}$ & $12 \mathrm{MPa}$ \\
\hline Tuffeau & Calcite, quartz, clays & $48 \%$ & $10 \mu \mathrm{m}$ & $0.45 \mathrm{~kg} \mathrm{~m}^{-2} \mathrm{~s}^{-0.5}$ & $10 \mathrm{MPa}$ \\
\hline Lutetiean "Roche Franche" & Calcite & $20 \%$ & $4.5 \mu \mathrm{m}$ & $0.045 \mathrm{~kg} \mathrm{~m}^{-2} \mathrm{~s}^{-0.5}$ & $33 \mathrm{MPa}$ \\
\hline Savonières & Calcite & $36 \%$ & Multi-modal & $0.068 \mathrm{~kg} \mathrm{~m}^{-2} \mathrm{~s}^{-0.5}$ & $16 \mathrm{MPa}$ \\
\hline
\end{tabular}




\subsection{Materials characterization methods}

Several experimental techniques are employed to determine materials physical properties and sensitivity to weathering. Continuous capillarity-rise experiments have been done in $5 \mathrm{~cm} * 5 \mathrm{~cm} * 25 \mathrm{~cm}$ stone samples. Video recording and weight monitoring have been done. $\mathrm{P}$ wave velocities and electrical conductivity have been measured at different height of the samples (every $2.5 \mathrm{~cm}$ ) and at different times.

Salt weathering cycles have been done with two salts (sodium chloride and sodium sulfate) and with a mixture of them. Testing procedure is based on the proposed procedure RILEM TC 271 ASM [1], samples are contaminated from the bottom and evaporation is allowed only on the upper side. For samples contaminated by $\mathrm{Na}_{2} \mathrm{SO}_{4}$ and salt mixture, wetting/drying cycles have been used and for samples contaminated by $\mathrm{NaCl}$ relative humidity cycles were performed. Two concentrations have been employed 3.1 and $6.7 \%$.

Thaw/freeze cycles have been done in the studied samples using the same salt solution than in previous tests.

In order to estimate vapor water uptake of samples with and without salt, we measured the evolution of weight with relative humidity increase and decrease in samples without salts and in samples with different amounts of salt with a Vsorp (ProUmid) apparatus. Two kinds of samples have been measured, samples contaminated with a prefixed solution concentration and $0.5 \mathrm{~cm}$ slices from salt weathering tests samples obtained at different heights.

\subsection{Weathering evolution with climate change studies}

Results from experimental tests are the base to establish the "weathering criteria" to be used to measure stone weathering. Using meteorological and climatic data and previously established criteria, we are able to predict the differences between past weathering and future one. The goal is to estimate the increase, decrease or maintenance of weathering degree due to different agents: liquid and vapor water, brine composition and concentration, climate parameters, water table height, etc. Employed methodology is similar the one developed in NOAH's ARK project [2, 3].

\section{Results}

Some preliminary results can be seen in figure 1 . Capillarity rise depends very much on the stone properties and that salt freeze/thaw weathering depends on the stone type and on the salt composition (type of salt and concentration). Climate evolution models preconize changes in mean climate values but also an increase of extreme events. Results show changes of mean relative humidity and temperature in the future climate in France, mainly during summer time that implies changes in weathering patterns.

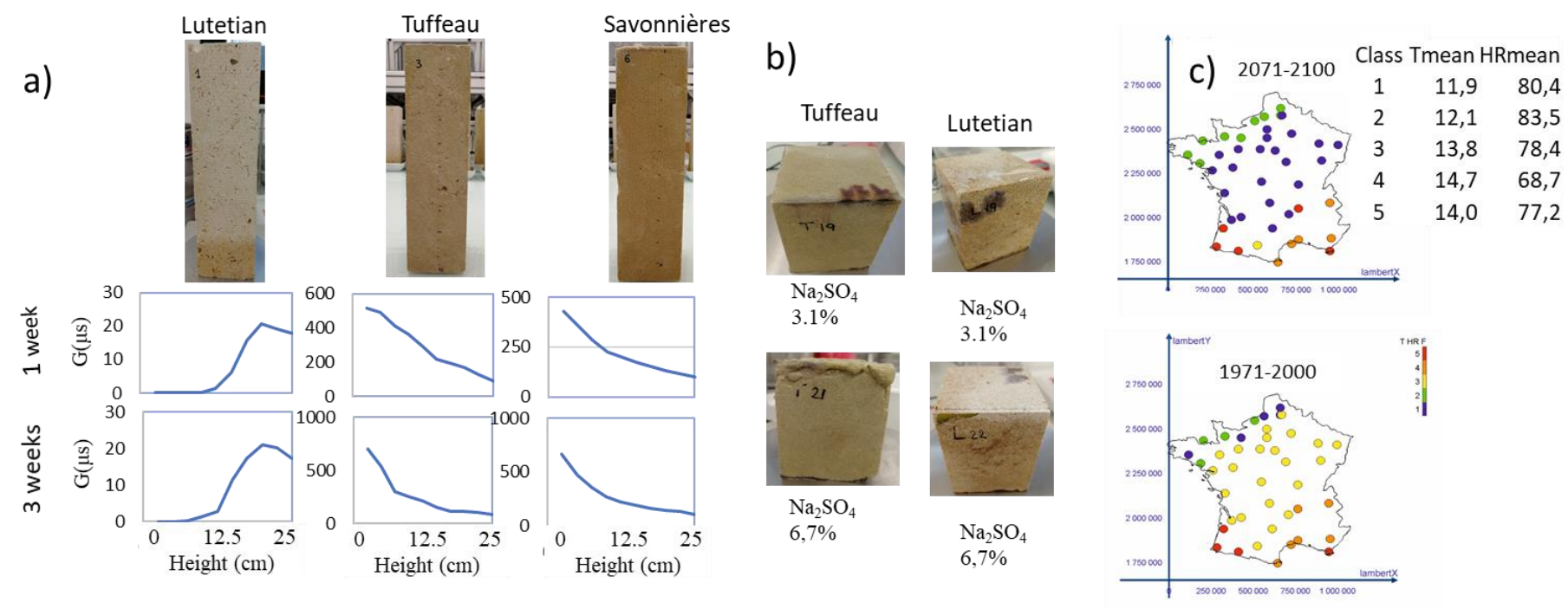

Figure 1. a) Humidity distribution after capillarity test. b) Samples after freeze/thaw cycles saturated with salt solutions. c) Changes in temperature and relative humidity conditions in France between past and future

\section{References}

[1] Lubelli B, Cnudde V, Diaz-Goncalves T, Franzoni E, Hees, van TPJ, Ioannou I, Menendez B, Nunes C, Siedel H, Stefanidou M, Verges-Belmin V, Viles H. 2018 "Towards a more effective and reliable salt crystallization test for porous building materials: state of the art" Materials and Structures. doi.org/10.1617/s11527-018-1180-5

[2] Sabbioni C, Brimblecombe P, Cassar M 2010 "The atlas of climate change impact on European cultural heritage. Scientific analysis and management strategies Anthem Press. ISBN 978-92-79-09800-0

[3] Menendez B. 2016. "Salt climatology applied to built cultural heritage", in: R.-A.Lefèvre, C. Sabbioni (Eds.), Cultural Heritage from Climate Change to GlobalChange, Edipuglia: Bari, Italy, 2016; pp. 35-50. 